\title{
СТАННИН В КОЛЧЕДАННЫХ РУДАХ ИМАНДРА-ВАРЗУГСКОЙ ЗОНЫ, ПЕРВАЯ НАХОДКА В КОЛЬСКОМ РЕГИОНЕ
}

\section{Карпов С.М., Чернявский А.В., Тележкин А.А., Савченко Е.Э.}

Геологический институт КНЦ РАН, Anamumbl, skarpov@geoksc.apatity.ru

Станнин относится к минералам класса сульфидов с общей формулой вида $\mathrm{Cu}_{2} \mathrm{FeSnS}_{4}$. Это довольно распространенный минерал, однако в большинстве случаев встречается в незначительных количествах и важного промышленного значения не имеет.

Кристаллическая структура станнина является аналогом структуры халькопирита, в которой половина атомов железа в тетраэдрах упорядоченно замещается атомами олова (рис. 1). Часто в составе минерала отмечается примесь цинка. Близким к станнину по составу является кестерит $\left(\mathrm{Cu}_{2}(\mathrm{Zn}, \mathrm{Fe}) \mathrm{SnS}_{4}\right)$, с которым станнин нередко находится в одном парагенезисе. Топологически структура этих минералов идентична, отличие заключается в ином распределении атомов металлов в кристаллической ячейке, что приводит к различным пространственным группам симметрии: I $\overline{4}$ $2 \mathrm{~m}$ для станнина и I $\overline{4}$ для кестерита $[9,10]$.

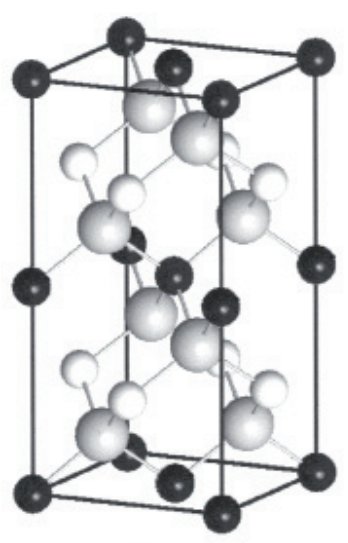

A

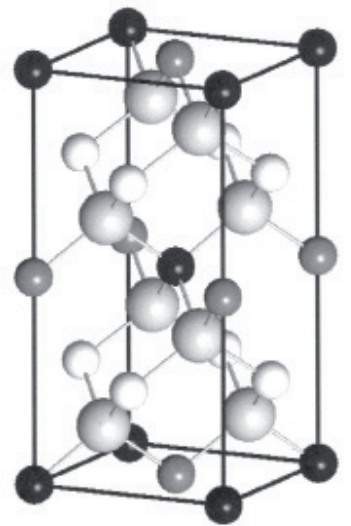

Б

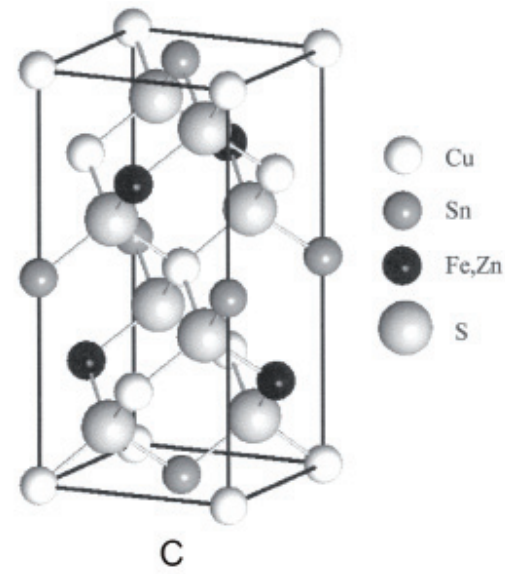

C

Рис. 1. Шариковые модели кристаллических структур халькопирита (А), станнина (Б) и кестерита (В) [5].

На территории Кольского региона этот минерал до недавнего времени достоверно установлен не был [1]. В то же время, на Фенноскандинавском щите станнин известен во многих регионах: в скарноворудных образованиях Питкярантского рудного района в Карелии, Россия [3], в рудах месторождений Оутокумпу, Финляндия [12], в колчеданном месторождении Виханти, Финляндия [6], в колчеданном месторождении Сулитьельма, Норвегия [8], в колчеданном месторождении Сатра, в Швеции [14] и на других объектах [11].

Станнин в пределах пояса Имандра-Варзуга (ИВСЗ) установлен нами на двух участках: в северо-западном блоке Панареченской вулкано-тектонической структуры (ПР ВТС) и в колчеданной залежи №2 Основного участка Южного Прихибинья (рис. 2).

ПР ВТС расположена в центральной части ИВСЗ и представляет собой автономную брахиформную структуру по зоне глубинного разлома, разделенной на два блока. В пределах северозападного блока выявлены золото-теллуридные проявления, которые приурочены к четырем типам рудоносных пород: сульфидно-углеродистым сланцам, серицит-карбонат-альбит-кварцевым метасоматитам, хлорит-карбонатным метасоматитам и массивным пиритовым рудам [7, 2]. С последним типом руд связана находка станнина. Пиритовые руды полосчатого, густо-вкрапленного типа, до массивных (рис. 3). Второстепенные и редкие минералы ассоциации - пирротин, халькопирит, сфалерит, тетраэдрит, алтаит, арсенопирит, алексит.

Колчеданные залежи западной части ИВСЗ Южного Прихибинья расположены вблизи контакта со щелочным массивом Хибин и разведывались в первой половине прошлого столетия на сульфидную серу. Руды чаще брекчиевидного (нерудные обломки, цемент сульфидный) и сетчатополосчатого типов (рис. 3). Главным сульфидным минералом руд является пирротин, в подчинен- 


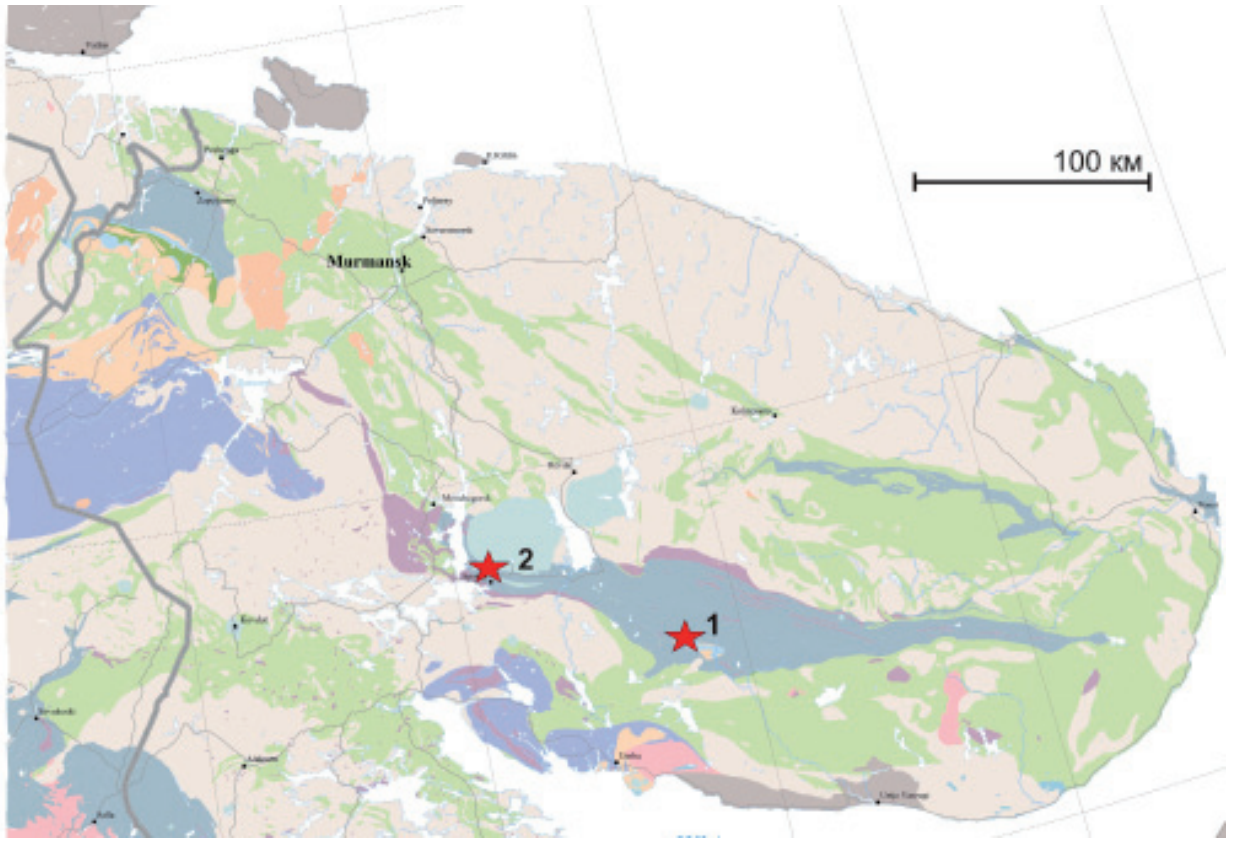

Рис. 2. Геологическая карта Кольского региона.

Участки ИВСЗ: 1 - Северо-западный блок Панареченской вулкано-тектонической структуры ПР ВТС; 2 - Основной участок, Южное Прихибинье.

ном количестве развит халькопирит и сфалерит. В качестве акцессорных минералов здесь присутствует молибденит, редко галенит и пирит. На отдельных участках залежей наблюдается обогащение руд халькопиритом, сфалеритом, пиритом и галенитом. Типоморфной для колчеданных проявлений Южного Прихибинья является акцессорная арсенопирит - лёллингитовая ассоциация, с которой тесно связана благороднометалльная минерализация [4].
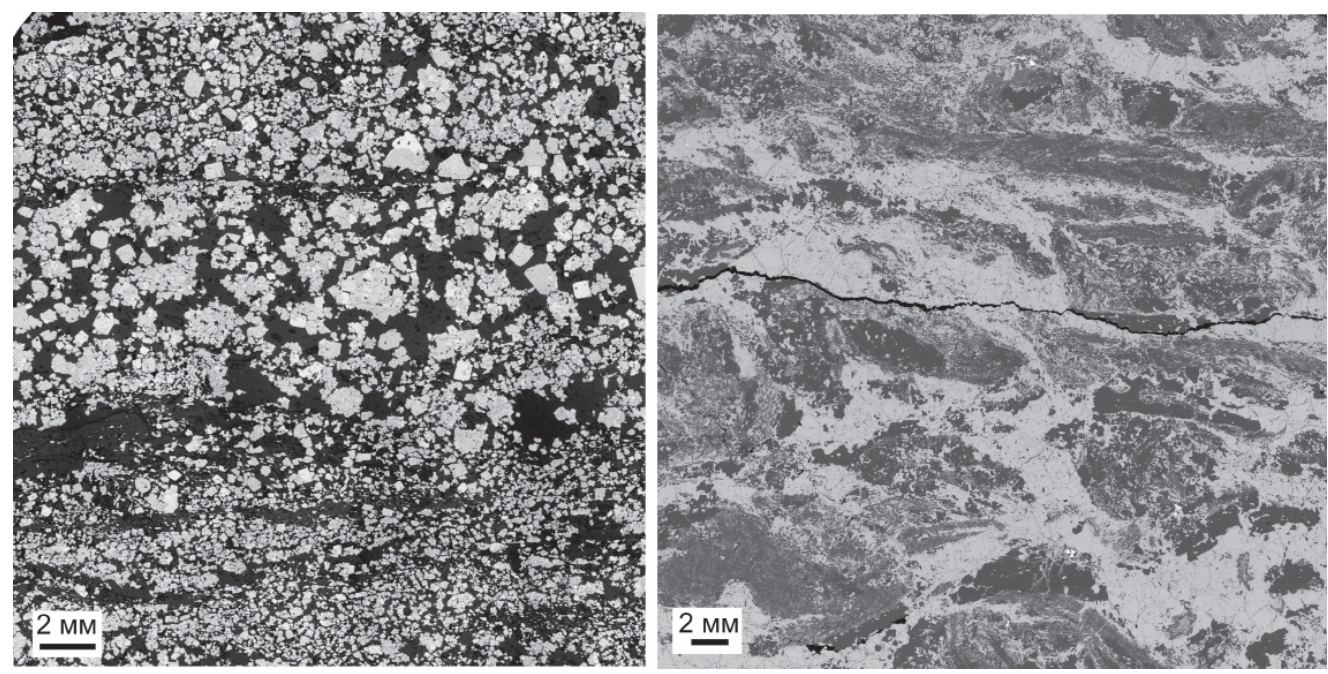

Рис. 3. Внешний вид колчеданных руд ИВСЗ.

Слева: пиритовые руды полосчатого, густо-вкрапленного типа, ПРВТС; справа: пирротиновые руды брекчиевидного типа, Южное Прихибинье. Фото фрагментов полированных образцов.

На участке ПР ВТС станнин установлен в образце из керна одной из скважин, вскрывшей пиритовые руды. Минерал выявлен внутри включения в пирите. Включение округлой формы размером 40×30 мкм представляет собой сложное срастание пирротина, халькопирита и станнина (рис. 4). Станнин в виде удлинённых зерен размером $2 \times 5$ мкм находится в межзерновом пространстве индивидов пирротина. Здесь же на границе халькопирита и пирротина присутствует тонкое включение Hg содержащей минеральной фазы. 

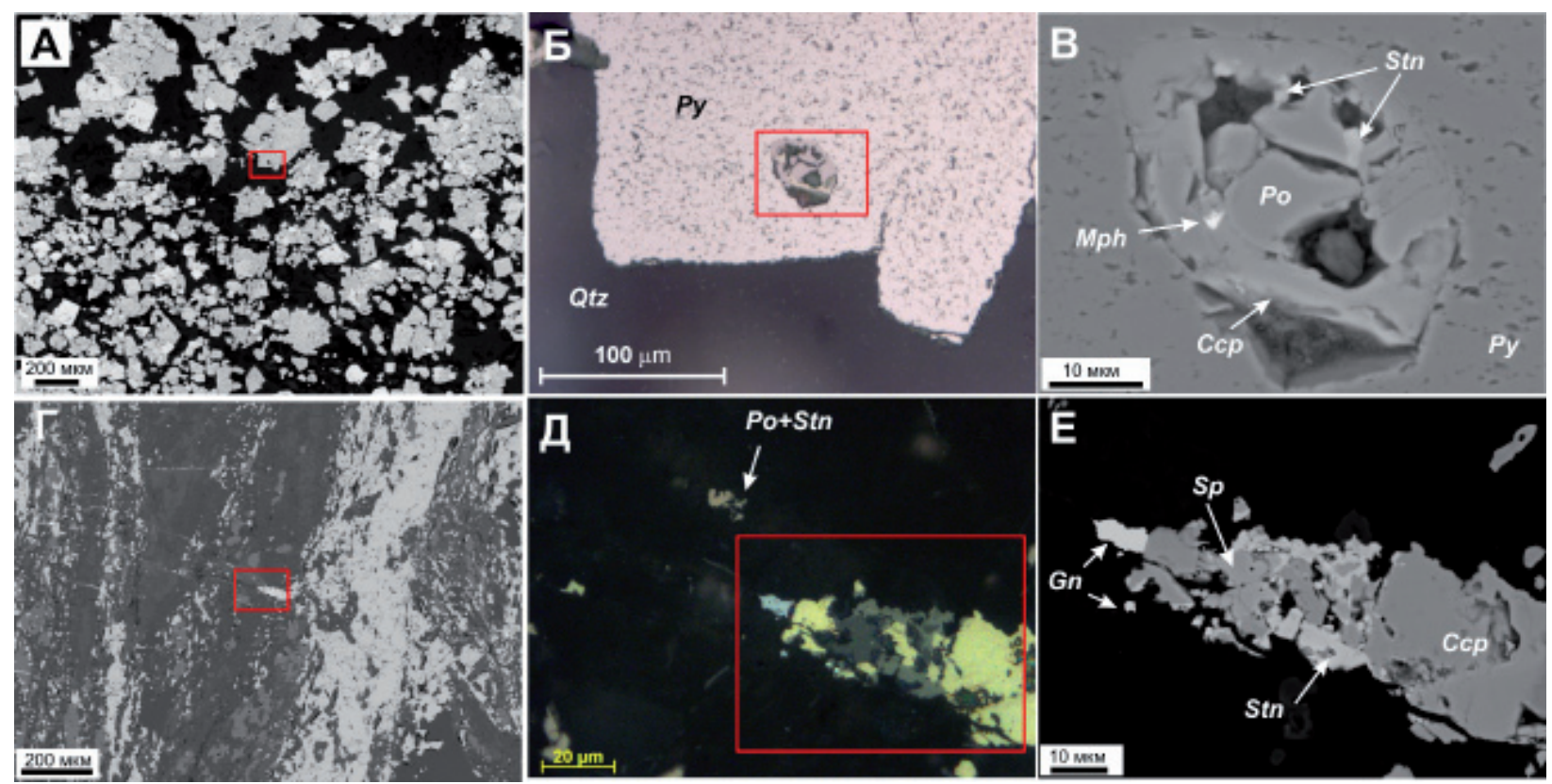

Рис. 4. Характер выделений станнина (Stn) в колчеданных рудах ИВС3.

Сверху - полосчатые густо-вкрапленные пиритовые руды ПР ВТС; снизу - сетчатые пирротиновые руды Основного участка, Южное Прихибинье). А, Б, Д - снимки в отраженном поляризованном свете; В, Г, Е - снимки в обратно рассеянных электронах; Ру - пирит; Ро - пирротин; Сср - халькопирит; Gn - галенит; $\mathrm{Sp}$ - сфалерит; Qtz - кварц; Mph - минеральная фаза состава $\left(\mathrm{Fe}_{4.46} \mathrm{Ag}_{2.23} \mathrm{Cu}_{1.98} \mathrm{Au}_{0.42} \mathrm{Zn}_{0.14}\right)_{9.24} \mathrm{Hg}_{2.07}\left(\mathrm{~S}_{6.39} \mathrm{Se}_{0.29}\right)_{6.69}$.

Станнин Южного Прихибинья выявлен в образце, характеризующем брекчиевидный тип пирротиновых руд залежи № 2 Основного участка. Минерал приурочен к поздним цеолитовым прожилкам, секущим нерудные «обломки», которые по минеральному составу условно отнесены нами к роговикам (кордиерит, флогопит, анортит, апатит, энстатит и др.). Станнин здесь находится в тесном срастании с халькопиритом и сфалеритом, локализуясь ближе к краевым частям агрегата вместе с галенитом (рис. 4). Наблюдаются также мелкие его сростки с пирротином. В отраженном поляризованном свете минерал светло-серого цвета оливкового оттенка, с показателем отражения выше сфалерита.

Химический состав станина, ввиду мелких его размеров, был оценен рентгеноспектральным методом с помощью энергодисперсионного спектрометра Bruker XFlash-5010, установленном на сканирующем электронном микроскопе LEO-1450. Содержание элементов приведено к 100 \% (табл. 1).

Таблица 1. Химический состав станнина из колчеданных руд ИВСЗ.

\begin{tabular}{|c|c|c|c|c|}
\hline \multirow{2}{*}{ Элементы } & \multicolumn{2}{|c|}{ ПР ВТС } & \multicolumn{2}{c|}{ Ю. Прихибинье } \\
\cline { 2 - 5 } & мас. \% & к.ф. ${ }^{*}$ & мас.\% & к.ф. \\
\hline $\mathrm{Cu}$ & 30.33 & 2.18 & 27.59 & 1.86 \\
$\mathrm{Sn}$ & 27.91 & 1.07 & 27.04 & 0.97 \\
$\mathrm{Fe}$ & 8.35 & 0.68 & 15.50 & 1.19 \\
$\mathrm{Zn}$ & 6.20 & 0.43 & - & \\
$\mathrm{Se}$ & 2.79 & 0.16 & - & \\
$\mathrm{S}$ & 24.43 & 3.48 & 29.87 & 3.98 \\
\hline Сумма & 100 & 8.00 & 100 & 8.00 \\
\hline
\end{tabular}

Примечание: * Формульные коэффициенты (к.ф.) рассчитаны на 8 атомов в теоретической формуле станнина.

Химический состав и рассчитанные формульные коэффициенты вполне согласуются с теоретическим и природными составами станнина, что хорошо видно на диаграммах соотношений металлов в оловосодержащих сульфидных минералах (рис. 5). Особенностью состава станнина из ПР 


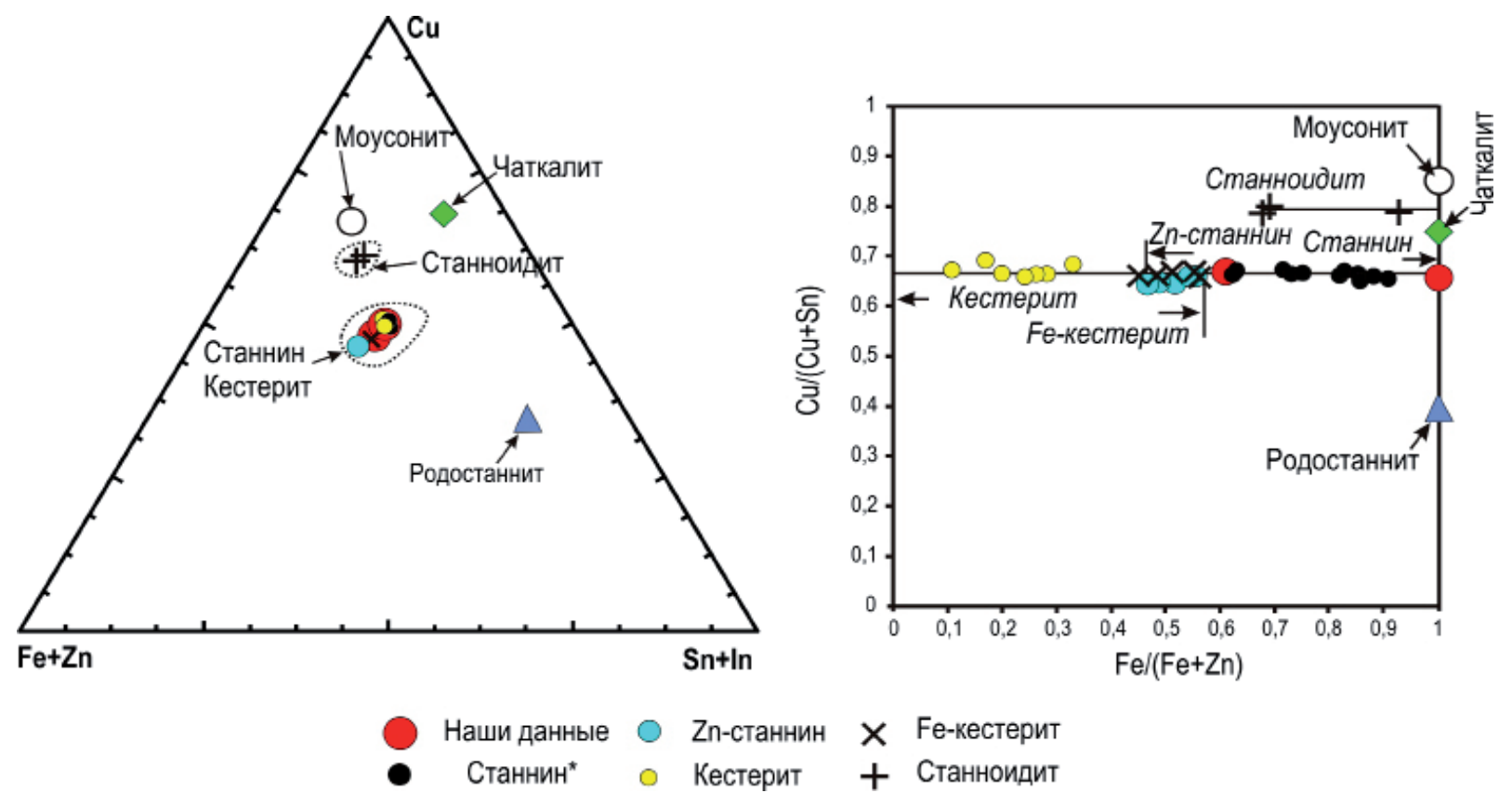

Рис. 5. Тройная (слева) и двойная (справа) диаграммы соотношения металлов, показывающие вариации составов в минералах ряда станнин - кестерит, а также других оловосодержащих минеральных видов [10, 12, 13].

ВТС является существенная примесь в катионной группе железа $-\mathrm{Zn}$ и в анионной $-\mathrm{Se}$. Состав станнина Южного Прихибинья близок к теоретическому.

Таким образом, на территории Кольского региона на двух разобщенных в пространстве участках протерозойской структуры ИВСЗ впервые установлен оловосодержащий сульфидный минерал, который по составу и частично свойствам в отраженном свете отвечает станнину.

Работа выполнена в рамках темы НИР ГИ КНЦ РАН № 0231-2015-0001.

\section{Литература}

1. Борисова В.В., Волошин А.В. Перечень минеральных видов Кольского региона. Изд. 5-е, испр. и доп. Апатиты: К\&M, 2015. 124 с.

2. Волошин А.В., Чернявский А.В., Войтеховский Ю.Л. Теллуридная минерализация в золоторудных проявлениях Панареченской вулкано-тектонической структуры, Кольский п-ов // Вестник КНЦ РАН. 2012. № 1. С. 66-79.

3. Иващенко В. И., Голубев А.И. Новые аспекты минералогии и металлогении Питкярантского рудного района // Труды КарНЦ РАН № 7. Петрозаводск, 2015. С. 127-148.

4. Карпов С. М., Волошин А. В. Генетическая минералогия золота и серебра в колчеданных рудах Прихибинья (Кольский полуостров) // Материалы международной конференции «Золото Фенноскандинавского щита» (1-5 октября 2013 г.). Петрозаводск. Карельский научный центр РАН. 2013. С. 77-80.

5. Костов И., Минчева-Стефанова Й. Сульфидные минералы. Кристаллохимия, парагенезис, систематика. Пер.с англ. М.: Мир. 1984. 281 с.

6. Сергеева Н.Е., Ерёмин Н.И., Дергачёв А.Л. Ванадиевая минерализация в рудах колчеданнополиметаллического месторождения Виханти (Финляндия) // ДАН. 2011. Т.436. № 6. С. 800-803.

7. Чернявский А.В., Войтеховский Ю.Л., Волошин А.В., Савченко Е.Э., Павлов В. А. Благороднометальная и сульфидная минерализация в породах панареченской вулкано-тектонической структуры // Tp. VI Всерос. Ферсмановской науч. сессии. Апатиты: изд-во КНЦ РАН, 2009. С. 151-156.

8. Cook N. J. Mineralogy of the sulphide deposits at Sulitjelma, northern Norway // Ore Geology Reviews. 1996. V. 11: P. 303-308.

9. Hall S.R., Szymanski J.T., Stewart J.M. Kesterite $\mathrm{Cu}_{2}(\mathrm{Zn}, \mathrm{Fe}) \mathrm{SnS}_{4}$, and stannite, $\mathrm{Cu}_{2}(\mathrm{Fe}, \mathrm{Zn}) \mathrm{SnS}_{4}$, structurally similar but distinct minerals // Can. Mineral. 1978. V. 16. P. 131-137.

10. Kissin S.A. and Owens D.R. New data on stannite and related tin sulfide minerals // Can. Mineral. 1979. V. 17. P. 125-135

11. Mindat.org https://www.mindat.org/min-3747.html (Current server date: March 13, 2018).

12. Peltonen P., Kontinen A., Huhma H., Kuronen U. Outokumpu revisited: New mineral deposit model for the mantle peridotite-associated $\mathrm{Cu}-\mathrm{Co}-\mathrm{Zn}-\mathrm{Ni}-\mathrm{Ag}-\mathrm{Au}$ sulphide deposits // Ore Geology Reviews, 2008. V. 33. P. 559-617.

13. Petruk W. Tin sulphides from the deposit of Brunswick Tin Mines Limited// Can. Mineral. 1973 V.12. P. 46-54.

14. Zakrzewski M.A., Burke E.F.J., Lustenhower W.J. Vuorelainenite, a new spinel, and associated minerals from 